Miami Nature Biotechnology Short Reports

TheScientificWorld (2001) 1 (S3), 139SR

ISSN 1532-2246; DOI 10.1100/tsw.2001.241

\title{
EXECUTION OF NECROTIC-LIKE CELL DEATH IN CAENORHABDITIS ELEGANS REQUIRES CATHEPSIN D ACTIVITY
}

\author{
Nektarios Tavernarakis*, Keli Xu, and Monica Driscoll \\ Department of Molecular Biology and Biochemistry, Rutgers University, 604 Allison Road, \\ Piscataway NJ 08855 \\ * tavernarakis@mbcl.rutgers.edu
}

INTRODUCTION. Inappropriate cell death underlies the pathology of many human and animal diseases. In particular, premature neuronal cell death plays a significant role in several late onset degenerative disorders such as Alzheimer's Disease and Amyotrophic Lateral Sclerosis (1). The mechanisms of execution of pathological or necrotic cell death are not clear, but a detailed molecular model of inherited neurodegenerative conditions, identified in the nematode Caenorhabditis elegans, is emerging and may provide a means of identifying a conserved pathway for pathological cell death in humans (2). Gain-of-function mutations in several, specific, C. elegans ion channel genes encode hyperactive channels that induce necrotic-like death of the neurons that express these channel genes. For example, dominant mutations in the mec-4 gene (mechanosensory; mec-4 allele $u 231$ or $d$ : dominant) induce degeneration of six touch receptor neurons required for the sensation of gentle touch to the body $(3,4)$. We are investigating the requirements for the progression and execution of degenerative cell death inflicted by mec-4(d) and other insults in C. elegans. To highlight the molecular events that transpire during neurodegeneration we have embarked on an effort to define conditions that block or interfere with necrotic-like cell death. We report here that Cathepsin D, which is an aspartyl protease, is required for the execution of necrotic-like cell death in C. elegans.

RESULTS. Several mutant nematode strains have been found to exhibit up to $90 \%$ reduced Cathepsin D protease activity (5). We assessed the requirement for Cathepsin D activity in necrotic-like cell death induced by mec-4(d), by testing the strains cad-1 alleles $j 2$ and $j 14$, daf4(e1364), mec-8(e398) and unc-52(su250) (known to have 80\%-90\% reduced Cathepsin D proteolytic activity) for effects in touch neuron degeneration. As shown in Table 1, necroticlike cell death induced by mec-4(d) was significantly blocked in these genetic backgrounds. Starvation is another condition that leads to significant reduction of Cathepsin D activity in $C$. elegans (6). We have observed that starvation also interferes with necrotic-like cell death induced by mec-4(d) (Table1). To further demonstrate the involvement of Cathepsin $\mathrm{D}$ proteolytic activity in neurodegeneration, we assayed the effects of Pepstatin A, a potent and specific inhibitor of Cathepsin D on mec-4(d) induced necrotic-like cell death. As shown in Table 1, Pepstatin A significantly blocked neurodegeneration. There are several genes in the completely sequenced $C$. elegans genome that encode putative Cathepsin D proteases. The most highly similar to biochemically characterized mammalian aspartyl proteases has been designated asp-4 (7). We employed dsRNA interference to quench asp-4 expression and to determine the effects on neurodegeneration. Results presented in Table 1 indicate that ASP-4 
activity is required for necrotic-like cell death induced by mec-4(d). Finally we tested the ability of asp-4 to suppress the effects of Cathepsin D deficient genetic backgrounds on mec4(d) induced necrotic-like cell death, when overexpressed. As shown in Table 1, overexpression of $a s p-4$ in a mec-4(d);cad-1(j2) completely reversed the suppressing effects of cad-1(j2) on mec-4(d)induced neurodegeneration.

Table 1. Cathepsin D is required for execution of necrotic-like cell death in C. elegans.

\begin{tabular}{|c|c|}
\hline Strain & \% 0 vacuoles \\
\hline$m e c-4(d)$ & $94 \pm 3$ \\
\hline$m e c-4(d), c a d-1(12)$ & $33 \pm 6$ \\
\hline$m e c-4(d), c a d-1014)$ & $41 \pm 5$ \\
\hline$m e c-4(d), d a f-4(e 1364)$ & $36 \pm 6$ \\
\hline$m e c-4(d), m e c-8(e 398)$ & $49 \pm 7$ \\
\hline$m e c-4(d), w n c-52(\mathrm{su} 250)$ & $43 \pm 4$ \\
\hline$m e c-4(d)$ Starwation & $68 \pm 9$ \\
\hline$m e c-4(d)$ Pepstatin $A$ & $32 \pm 8$ \\
\hline$m e c-4(d) \alpha s p-4_{\mathrm{dgRHAi}}$ & $42 \pm 9$ \\
\hline$m e c-4(d), c a d-1(02)$ asp-4 $4^{\mathrm{High}}$ & $89 \pm 8$ \\
\hline
\end{tabular}

DISCUSSION. Aspartyl proteases such as Cathepsin D are mostly lysosomal enzymes but they have also been found to function in the cytoplasm. Among several metabolic pathways, Cathepsin D has been implicated in endocytic degradation of proteins (8). Interestingly, degenerative cell death involves extensive plasma membrane internalization that resembles endocytosis (9). Such a process may require the function of Cathepsin D. Our results suggest that Cathepsin $\mathrm{D}$ activity plays a pivotal role in the disorganization and destruction of the cellular content during neurodegeneration that has been inflicted by mec-4(d) in C. elegans. To determine how general the requirement for aspartyl protease activity is, we are investigating the involvement of Cathepsin D in necrotic-like cell death, induced by insults other than mec$4(d)$, in the nematode. If a central role for cathepsin D in the execution of degenerative cell death is established, such proteases could become attractive therapeutic targets that when inactivated might significantly delay or block the progression of inappropriate cell death.

\section{REFERENCES.}

1. Honig, L.S. and Rosenberg, R.N. (2000) Am. J. Med. 108, 317-330

2. $\quad$ Chalfie, M. and Wolinsky, E. (1990) Nature 345, 410-416

3. $\quad$ Driscoll, M. and Chalfie, M. (1991) Nature 349, 588-593

4. Tavernarakis, N. and Driscoll, M. (1997) Annu. Rev. Physiol. 59, 659-689

5. Jacobson, L.A., Jen-Jacobson, L., Hawdon, J.M., Owens, G.P., Bolanowski, M.A., Emmons, S.W., Shah, M.V., Pollock, R.A., and Conklin, D.S. (1988) Genetics 119, 355-363

6. Sarkis, G.J., Ashcom, J.D., Hawdon, J.M., and Jacobson, L.A. (1988) Mech. Ageing Dev. 45, 191-201

7. Tcherepanova, I., Bhattacharyya, L., Rubin, C.S., and Freedman, J.H. (2000) J. Biol. Chem. 275, 26359-26369 
8. $\quad$ Blum, J.S., Fiani, M.L., and Stahl, P.D. (1991) J. Biol. Chem. 266, 22091-22095

9. Hall, D.H., Gu, G., Garcia-Anoveros, J., Gong, L., Chalfie, M., and Driscoll, M. (1997) J. Neurosci. 17, 1033-1045 

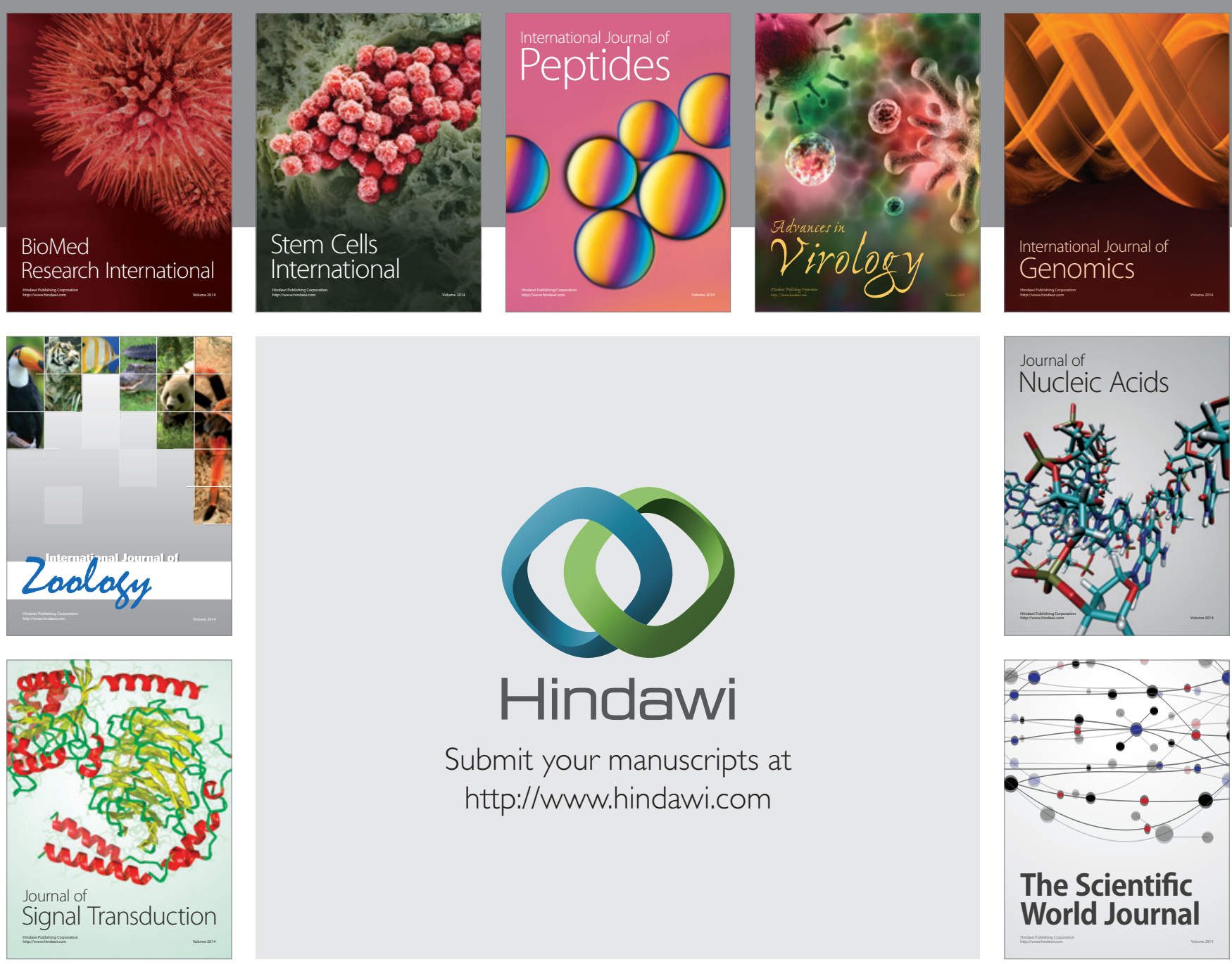

Submit your manuscripts at

http://www.hindawi.com
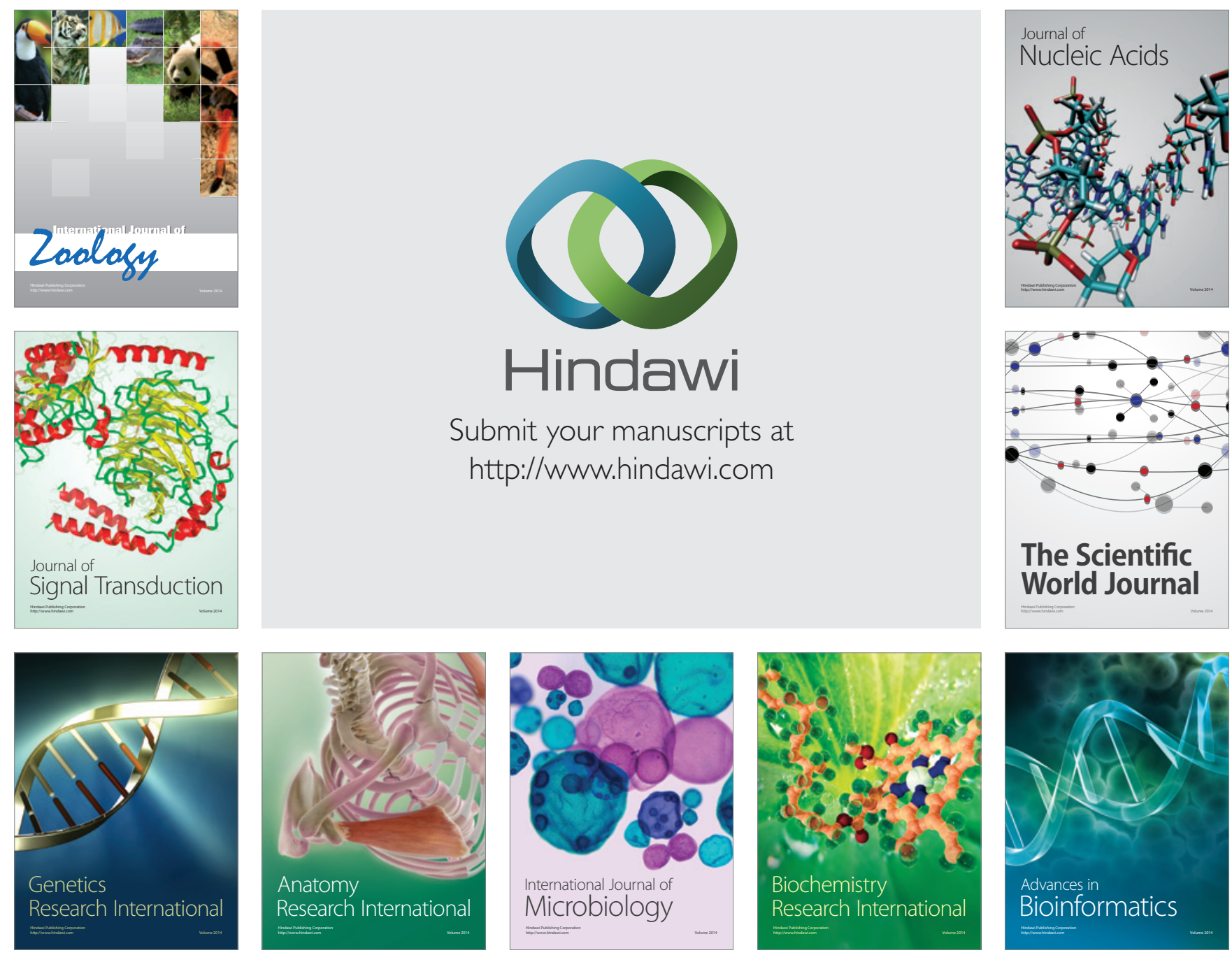

The Scientific World Journal
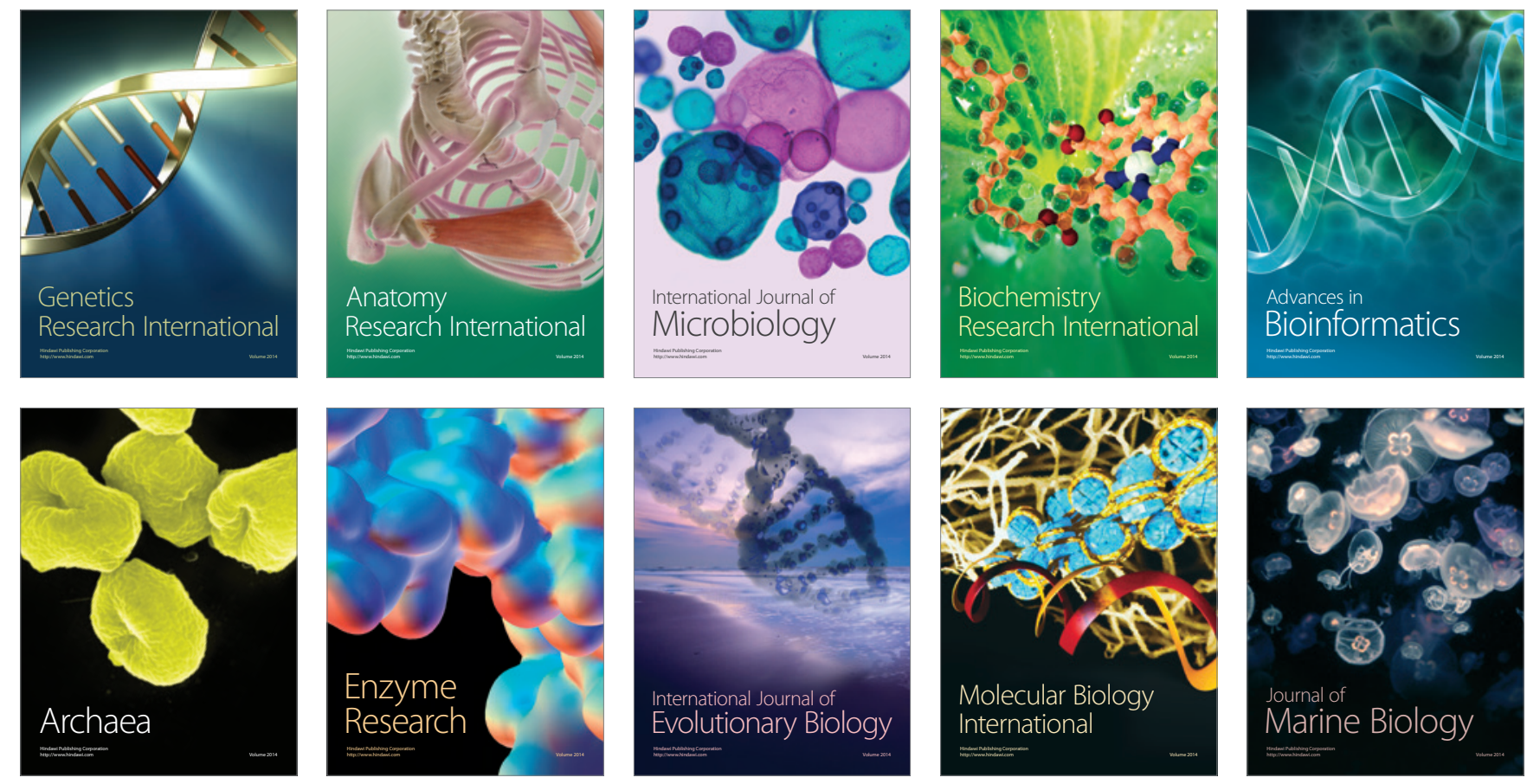